05

\title{
Влияние температуры термомеханической обработки на гетерогенную структуру углеродного волокна
}

\author{
(c) В.А. Тюменцев, ${ }^{1}$ А.Г. Фазлитдинова, ${ }^{1}$ С.А. Подкопаев ${ }^{2}$ \\ 1 Челябинский государственный университет, \\ 454001 Челябинск, Россия \\ 2 Завод углеродных и композиционных материалов, \\ 454038 Челябинск, Россия \\ e-mail: tyum@csu.ru
}

Поступило в Редакцию 13 декабря 2018 г.

В окончательной редакции 20 мая 2019 г.

Принято к публикации 10 июня 2019 г.

Методом рентгеноструктурного анализа изучено изменение тонкой структуры углеродных волокон по мере повышения температуры термомеханической обработки. Показано, что материал волокон гетерогенен, его компонентный состав определен режимами термомеханической обработки, а также зависит от угла $\varphi$ ориентировки областей когерентного рассеяния относительно оси нити.

Ключевые слова: углеродное волокно, рентгеноструктурный анализ, фазовый состав, текстура.

DOI: $10.21883 / J T F .2019 .12 .48483 .429-18$

\section{Введение}

Углеродные волокна (УВ), получаемые на основе полиакрилонитрила, широко применяются при производстве конструкционных композиционных материалов, обеспечивающих технический прогресс. Это обусловлено высокими физико-механическими характеристиками УВ, которые определяются условиями термомеханической обработки исходной полиакрилонитрильной (ПАН) нити на стадии термостабилизации и высокотемпературной обработки. При температуре от $\sim 220$ до $\sim 270^{\circ} \mathrm{C}$ в объеме полимерной матрицы развивается формирование структуры термостабилизированного волокна [1-5]. В процессе дальнейшей перекристаллизации материала термостабилизированной нити в инертной среде при высокой $\left(1500-3000^{\circ} \mathrm{C}\right)$ температуре формируется конечная структура, определяющая свойства УВ. Исследованию взаимосвязи режимов термомеханической обработки и структурных характеристик (средних размеров областей когерентного рассеяния, межслоевого расстояния $d_{002}$ и параметров текстуры), а также структуры и упруго-прочностных свойств волокна посвящено большое количество работ, например [6-11]. Так, авторами [9] приведены данные по взаимосвязи плотности углеродного волокна и прочности, модуля упругости, параметра текстуры и средних размеров ОКР $L_{002}$. В $[10,11]$ рассмотрено изменение $d_{002}$, размеров $L_{002}$ и $L_{110}$, упруго-прочностных свойств и параметра текстуры от температуры обработки в интервале от 1800 до $3000^{\circ} \mathrm{C}$, а также влияние вытягивающей нагрузки на изменение $d_{002}, L_{002}$ и $L_{110}$ при $2400^{\circ} \mathrm{C}$.

Однако на рентгенограммах УВ наблюдается существенная асимметрия максимумов 002, 004, 006. Это, как отмечается в [12], может быть обусловлено одновременным присутствием в материале компонент, заметно отличающихся по величине межслоевого расстояния и размерам ОКР. Поэтому традиционно вычисляемые по интегральной ширине и положению центра тяжести таких асимметричных максимумов данные не отражают реальную структуру материала. В [12] предложена методика получения новых данных о тонкой структуре УВ путем анализа профиля асимметричных дифракционных максимумов 002, 004 и 006. Показано, что в материале углеродного волокна формируется дискретный набор ОКР (компонент), отличающихся межслоевым расстоянием и средними размерами.

Следует отметить, что дискретные состояния углеродного материала, отличающиеся значением $d_{002}$, обнаружены при исследовании влияния добавки углеродных нанотрубок в исходный полимер на процесс формирования конечной структуры при низкотемпературной $\left(\sim 1100^{\circ} \mathrm{C}\right)$ графитации ПАН [13]. Методом просвечивающей электронной микроскопии высокого разрешения выявлены области когерентного рассеяния, образовавшиеся в непосредственной близости от нанотрубок, межплоскостное расстояние $d_{002}$ которых находится в пределах от $\sim 0.337$ до $\sim 0.37 \mathrm{~nm}$. Наличие дискретных состояний, отличающихся значением $d_{002}$, отмечается в работах [14-18], в которых рассмотрен процесс графитации углеродных материалов.

Таким образом, приведенные литературные данные указывают на возможность формирования гетерогенной структуры в процессе высокотемпературной обработки углеродных материалов. Показано также, что анализ асимметричных профилей рентгеновских дифракционных максимумов позволяет получить новые данные о тонкой структуре УВ. В настоящей работе методом рентгеноструктурного анализа изучена взаимосвязь между условиями высокотемпературной термомеханической обработки и тонкой структурой УВ. 

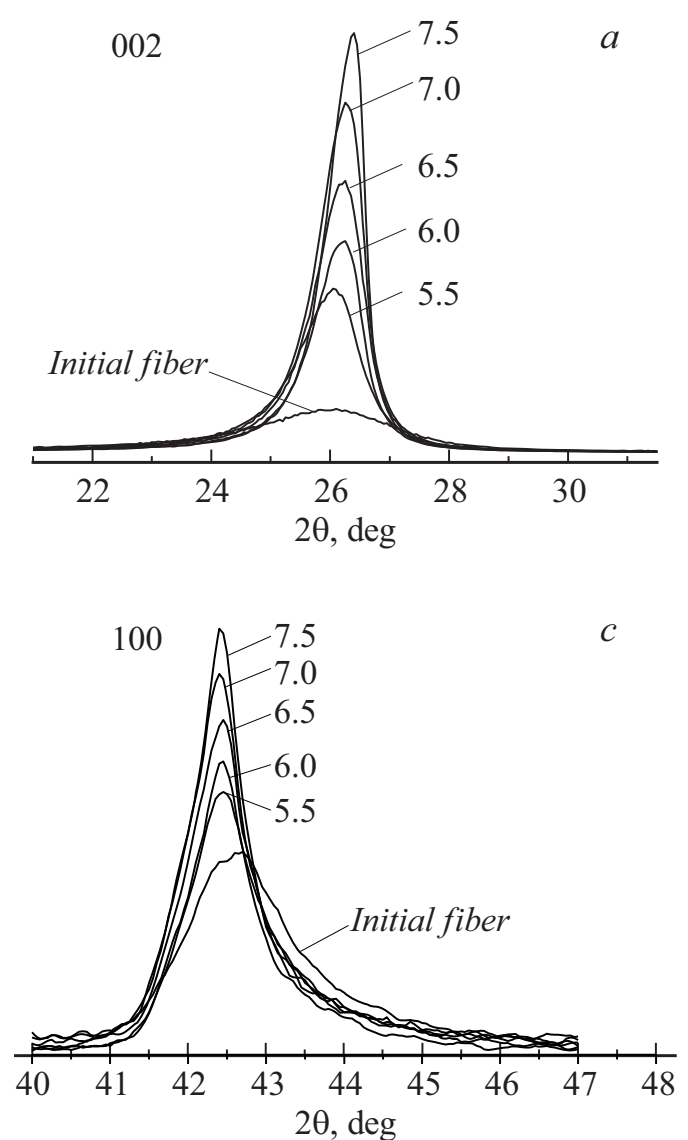
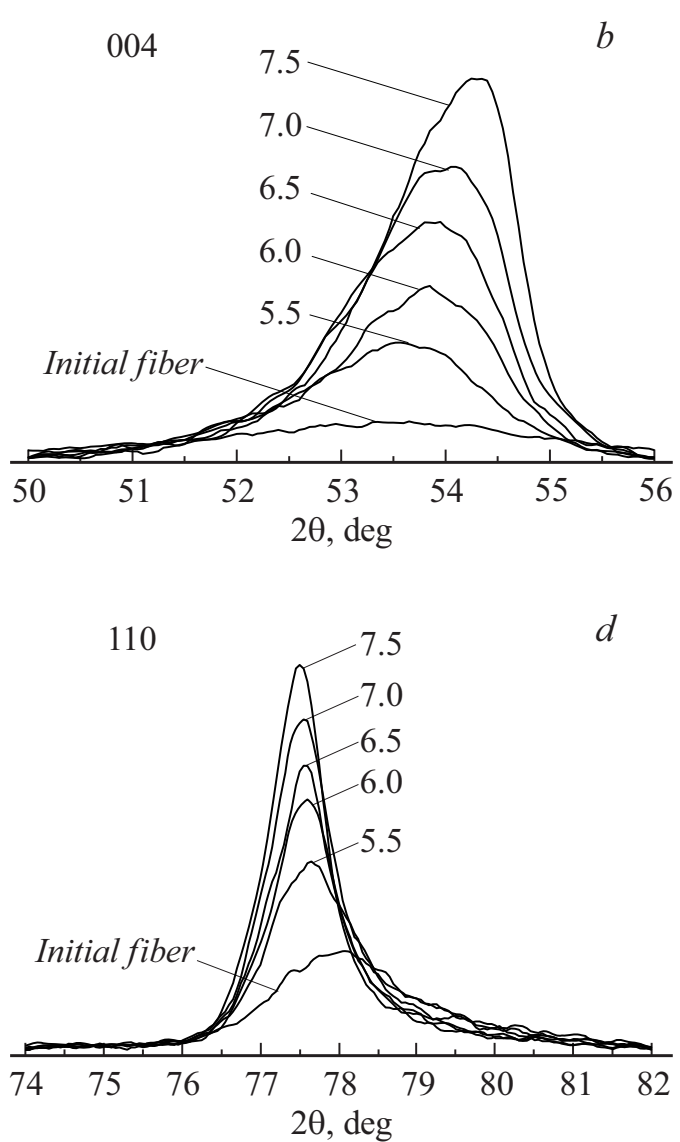

Рис. 1. Профили дифракционных максимумов $002(a), 004(b), 100(c)$ и $110(d)$, формируемых ОКР, ориентированными относительно оси углеродного волокна под углом $\varphi=0$ degree. Относительное удлинение волокон $\ell / \ell_{0}$ в процессе высокотемпературной обработки $7.5,7.0,6.5,6.0$ и $5.5 \%$.

\section{Объекты и методы исследования}

Для исследования в качестве исходного материала использовали УВ на основе полиакрилонитрила, полученные при $\sim 2300^{\circ} \mathrm{C}$. В процессе дополнительной термомеханической обработки в атмосфере аргона при температуре до $\sim 3000^{\circ} \mathrm{C}$ к жгуту волокна, содержащего 7200 филаментов, была приложена постоянная вытягивающая нагрузка $P=1.5 \mathrm{~kg}$. При проведении эксперимента температуру печи устанавливали таким образом, чтобы под действием нагрузки $P$ обеспечить увеличение длины жгута $\ell / \ell_{0}$ в интервале 5.5-7.5\% (продолжительность термообработки оставалась одинаковой).

Рентгеноструктурные исследования УВ выполнены с помощью рентгеновского дифрактометра D8 ADVANCE, фильтрованное $\mathrm{Cu} K_{\alpha}$-излучение. Для обеспечения условия самофокусировки дифрагированного пучка по Брэггу-Брентано всем исследуемым объемом углеродного волокна, его располагали в виде тонкого $(\sim 0.1 \mathrm{~mm})$ слоя нитей. При получении данных о текстуре материала по заданной программе с шагом $1^{\circ}$ записывали дифракционные максимумы 002 и 004 ОКР, ориентированных относительно оси нити в угловом интервале $\varphi= \pm 10^{\circ}$. Разделение асимметричных дифракционных максимумов 002 и 004 на минимальное коли-
Таблица 1. Параметры структуры, вычисленные по центру тяжести и интегральной ширине асимметричных дифракционных максимумов 002, 004, 110. Угол ориентировки ОКР относительно оси нити $\varphi=0^{\circ}$

\begin{tabular}{c|c|c|c|c|c|c}
\hline $\begin{array}{c}\text { Вытяжка УВ, } \\
\%\end{array}$ & $\begin{array}{c}d_{002}, \\
\mathrm{~nm}\end{array}$ & $\begin{array}{c}L_{002}, \\
\mathrm{~nm}\end{array}$ & $\begin{array}{c}d_{100}, \\
\mathrm{~nm}\end{array}$ & $\begin{array}{c}L_{100}, \\
\mathrm{~nm}\end{array}$ & $\begin{array}{c}d_{110}, \\
\mathrm{~nm}\end{array}$ & $\begin{array}{c}L_{110}, \\
\mathrm{~nm}\end{array}$ \\
\hline Исходное УВ & 0.03495 & 0.31 & 0.02109 & 0.62 & 0.1222 & 0.31 \\
5.5 & 0.3459 & 7.1 & 0.2116 & 8.8 & 1.225 & 9.3 \\
6.0 & 0.3435 & 7.3 & 0.2121 & 10.5 & 1.228 & 12.5 \\
6.5 & 0.3433 & 7.6 & 0.2120 & 10.4 & 1.229 & 13.5 \\
7.0 & 0.3429 & 8.6 & 0.2121 & 10.8 & 1.229 & 13.5 \\
7.5 & 0.3414 & 9.0 & 0.2125 & 13.0 & 1.231 & 15.7
\end{tabular}

чество симметричных, описываемых функцией Гаусса, проводили используя Origin 8. Для регистрации дифракционных максимумов 110 были приготовлены образцы, представляющие собой балочки сечением $5 \times 5 \mathrm{~mm}$ и длиной $10 \mathrm{~mm}$, состоящие из параллельно уложенных жгутов УВ (связующее - эпоксидная смола). Для записи рентгенограмм плоскость образца, которая нормальна оси нитей, совмещали с плоскостью самофокусировки рентгеновского пучка. Межплоскостное расстояние и 
Таблица 2. Компонентный состав и параметры структуры углеродных волокон, полученных при температурах, обуславливающих вытяжку жгута при постоянной нагрузке от 5.5 до $7.5 \%$

\begin{tabular}{|c|c|c|c|c|c|c|c|c|c|}
\hline \multirow{2}{*}{\multicolumn{2}{|c|}{$\begin{array}{c}\text { Вытяжка (\%) и } \\
\text { компоненты } \\
\text { разложения }\end{array}$}} & \multicolumn{2}{|c|}{$\varphi=0^{\circ}$} & \multicolumn{2}{|c|}{$\varphi=2^{\circ}$} & \multicolumn{2}{|c|}{$\varphi=4^{\circ}$} & \multicolumn{2}{|c|}{$\varphi=6^{\circ}$} \\
\hline & & \multirow{3}{*}{$\begin{array}{c}\begin{array}{c}d, \\
\mathrm{~nm}\end{array} \\
0.338 \\
0.341\end{array}$} & \multirow{2}{*}{$\begin{array}{c}\begin{array}{c}L, \\
\mathrm{~nm}\end{array} \\
34.3\end{array}$} & \multirow{2}{*}{$\begin{array}{c}\begin{array}{c}d, \\
\mathrm{~nm}\end{array} \\
0.338\end{array}$} & \multirow{2}{*}{$\begin{array}{c}\begin{array}{c}L, \\
\mathrm{~nm}\end{array} \\
24.3\end{array}$} & \multirow[t]{2}{*}{$\begin{array}{c}d, \\
\mathrm{~nm}\end{array}$} & \multirow[t]{2}{*}{$\begin{array}{c}L, \\
\mathrm{~nm}\end{array}$} & \multirow[t]{2}{*}{$\begin{array}{c}d, \\
\mathrm{~nm}\end{array}$} & \multirow[t]{2}{*}{$\begin{array}{c}L, \\
\mathrm{~nm}\end{array}$} \\
\hline 7.5 & $K_{2}$ & & & & & & & & \\
\hline & $K_{3}$ & & 16.6 & 0.341 & 13.5 & 0.339 & 18.8 & 0.340 & 14.1 \\
\hline & $K_{4}$ & & & & & 0.342 & 10.6 & 0.343 & 8.3 \\
\hline & $K_{5}$ & 0.344 & 6.7 & 0.345 & 5.3 & 0.347 & 4.5 & 0.349 & 3.5 \\
\hline \multirow[t]{4}{*}{7.0} & $K_{2}$ & 0.338 & 21.1 & 0.339 & 20.1 & & & & \\
\hline & $K_{3}$ & & & & & 0.340 & 16.2 & 0.340 & 17.5 \\
\hline & $K_{4}$ & 0.342 & 12.1 & 0.342 & 11.2 & 0.342 & 9.0 & 0.343 & 8.5 \\
\hline & $K_{5}$ & 0.345 & 4.9 & 0.346 & 3.8 & 0.348 & 3.7 & 0.348 & 3.5 \\
\hline \multirow[t]{4}{*}{6.5} & $K_{3}$ & 0.340 & 20 & 0.340 & 17.7 & 0.341 & 15 & 0.3410 & 13.8 \\
\hline & $K_{4}$ & 0.342 & 11 & 0.343 & 10 & & & & \\
\hline & $K_{5}$ & 0.346 & 4.4 & 0.348 & 4 & 0.344 & 7.2 & 0.3446 & 6.5 \\
\hline & $K_{6}$ & & & & & 0.351 & 2.8 & 0.350 & 3.2 \\
\hline \multirow[t]{4}{*}{6.0} & $K_{3}$ & 0.339 & 24.1 & 0.339 & 20.7 & 0.340 & 15.6 & 0.341 & 13.4 \\
\hline & $K_{4}$ & 0.342 & 12.2 & 0.342 & 10.9 & 0.343 & 8.7 & 0.343 & 7.4 \\
\hline & $K_{5}$ & 0.346 & 5.0 & 0.347 & 4.4 & 0.349 & 3.6 & & \\
\hline & $K_{6}$ & & & & & & & 0.350 & 3.2 \\
\hline \multirow[t]{4}{*}{5.5} & $K_{3}$ & 0.341 & 18.9 & & & & & & \\
\hline & $K_{4}$ & & & 0.342 & 12.1 & 0.342 & 11.4 & 0.342 & 9.9 \\
\hline & $K_{5}$ & 0.344 & 8.3 & 0.346 & 6.2 & 0.345 & 6.0 & 0.346 & 5.1 \\
\hline & $K_{6}$ & 0.351 & 3.5 & 0.356 & 2.3 & 0.356 & 2.3 & 0.357 & 2.1 \\
\hline
\end{tabular}

средние размеры ОКР вычисляли по центру тяжести и интегральной ширине экспериментально наблюдаемых и выделенных симметричных компонент (полагали, что физическое уширение максимума обусловлено только дисперсностью).

\section{Результаты и обсуждение}

На рентгенограммах исходных и прошедших дополнительную высокотемпературную обработку УВ отчетливо фиксируются асимметричные дифракционные максимумы 002, 004, а также максимумы 100 и 110 (рис. 1). Первоначально по традиционной методике по интегральной ширине и положению центра тяжести асимметричных максимумов были вычислены средние размеры ОКР и межплоскостные расстояния (табл. 1). Как следует из данных, приведенных в табл. 1, средние размеры ОКР $L_{002}, L_{100}$ и $L_{110}$ по мере повышения температуры дополнительной термомеханической обработки (увеличения относительного удлинения при постоянной нагрузке) постепенно возрастают на $\sim 27, \sim 48$ и $\sim 69 \%$ соответственно. При этом среднее значение $d_{002}$ уменьшается от 0.3495 до $0.3414 \mathrm{~nm}$, а значения $d_{100}$ и $d_{110}$ увеличиваются от 0.2109 до 0.2125 и от 0.1222 до $0.1231 \mathrm{~nm}$ соответственно.

Параметр $Z$ определяет интервал значений отклонений рентгеновского пучка, первоначально ориентированного под брэгговским углом $2 \theta$, равным $\sim 26.3^{\circ}$, к ОКР, параллельным оси нитей, при которых интенсивность рентгеновского излучения уменьшается в

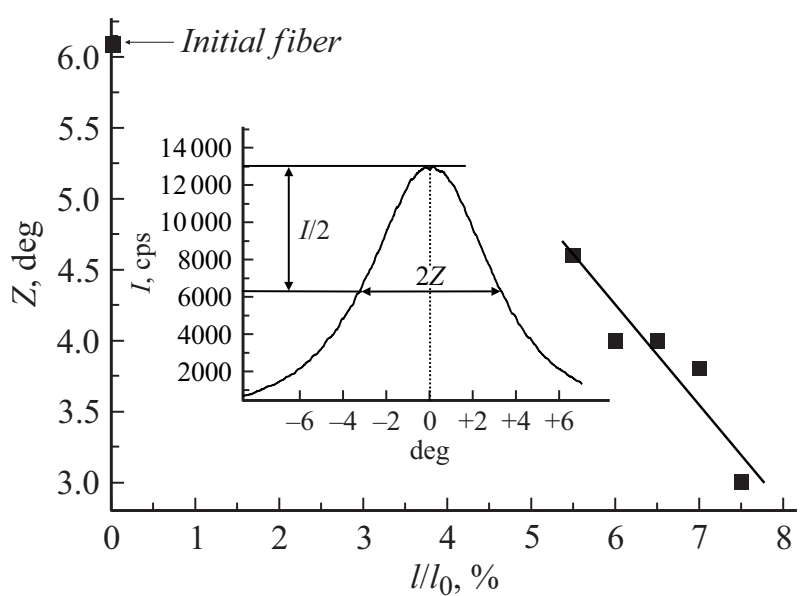

Рис. 2. Взаимосвязь относительного удлинения углеродных волокон $\ell / \ell_{0}$ в процессе высокотемпературной обработки и параметра текстуры $Z$. Во вставке приведена кривая изменения интенсивности максимума 002 при увеличении угла $\varphi$ ориентировки ОКР относительно оси нитей от 0 до $8^{\circ}$.

два раза (рис. 2) и характеризует текстуру УВ. Как видно из данных, приведенных на рис. 2, эта величина уменьшается от 4.6 до $3^{\circ}$ при увеличении вытяжки жгута от 5.5 до $7.5 \%$ и сокращается в два раза по сравнению с исходным волокном $\left(Z=6.1^{\circ}\right)$.

Таким образом, повышение температуры обработки в условиях действия вытягивающей нагрузки стимули- 


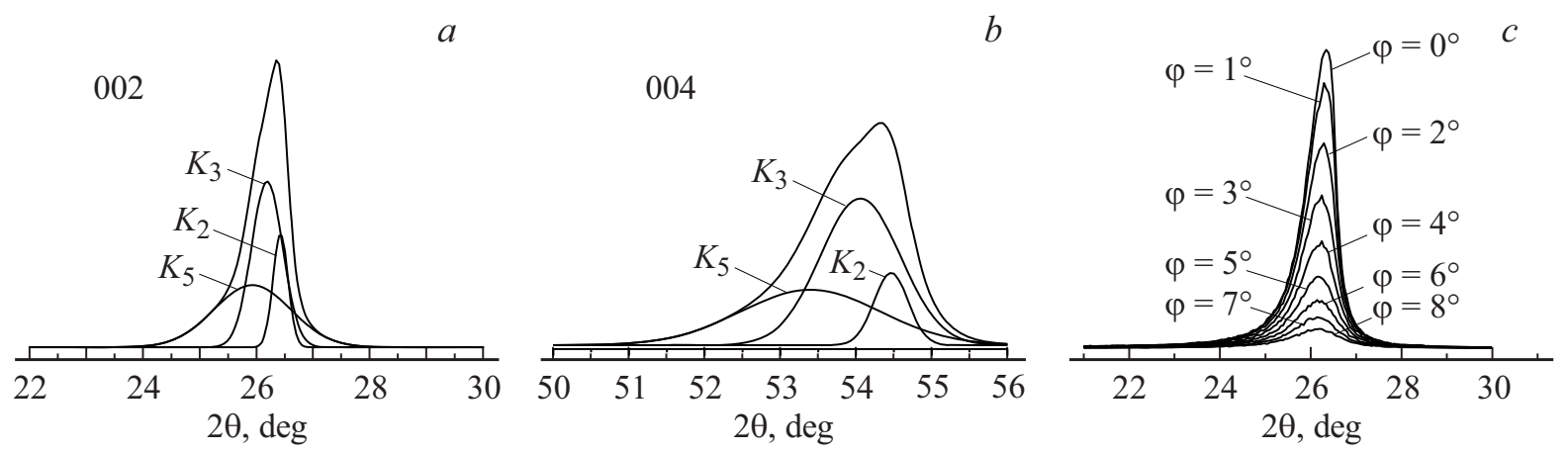

Рис. 3. Разделение асимметричных максимумов 002 и 004 на компоненты $(a, b)$; профили дифракционных максимумов 002 ОКР, ориентированных под углом $\varphi$ от 0 до $8^{\circ}$ к оси нити $(c)$. Относительное удлинение УВ $7.5 \%$.

Таблица 3. Компонентный состав и параметры структуры углеродных волокон, полученных при температурах, обуславливающих вытяжку при постоянной нагрузке 7.5 и $7.0 \%$ и рассчитанные по результатам разделения максимумов 002, 004

\begin{tabular}{c|c|rr|rr}
\hline \multirow{2}{*}{$\begin{array}{c}\ell / \ell_{0}, \\
\%\end{array}$} & \multirow{2}{*}{$\begin{array}{c}\text { Компо- } \\
\text { ненты }\end{array}$} & \multicolumn{2}{|c|}{$\begin{array}{c}\text { Максимум 002, } \\
\varphi=0^{\circ}\end{array}$} & \multicolumn{2}{c}{$\begin{array}{c}\text { Максимум 004, } \\
\varphi=0^{\circ}\end{array}$} \\
\cline { 3 - 6 } & & $d, \mathrm{~nm}$ & $L, \mathrm{~nm}$ & $d, \mathrm{~nm}$ & $L, \mathrm{~nm}$ \\
\hline 7.5 & $K_{2}$ & 0.3375 & 34.3 & 0.3370 & 27 \\
& $K_{3}$ & 0.3405 & 16.6 & 0.3394 & 9.8 \\
& $K_{5}$ & 0.3438 & 6.7 & 0.3434 & 5.5 \\
7.0 & $K_{2}$ & 0.3382 & 21.1 & 0.3376 & 22.9 \\
& $K_{4}$ & 0.3417 & 12.1 & 0.3400 & 8.5 \\
& $K_{5}$ & 0.3454 & 4.9 & 0.3450 & 5.4
\end{tabular}

рует массоперенос - наблюдается достаточно плавное увеличение средних размеров ОКР, при этом среднее значение межслоевого расстояния $d_{002}$ уменьшается, происходит существенное текстурирование материала. Однако при таком стандартном анализе полученных экспериментально данных теряется информация о тонкой структуре УВ (наблюдается существенная асимметрия дифракционных максимумов), которая может во многом определять его эксплуатационные свойства. Поэтому для получения дополнительной информации о тонкой структуре УВ необходимо проанализировать компонентный состав асимметричных максимумов (разложить их на симметричные компоненты).

Поскольку исследуемый образец тонкий и для всего исследуемого объема углеродного волокна выполняется условие самофокусировки дифрагированного пучка, будем считать, что асимметрия максимумов 002 и 004 обусловлена только структурными особенностями одновременным присутствием в углеродном материале нескольких метастабильных состояний (областей когерентного рассеяния, отличающихся, как минимум, значением $\left.d_{002}\right)$. В работах [14-18] отмечается, что в углеродном материале могут реализоваться состояния, которым соответствуют фиксированные значения межслоевого расстояния: $d_{002}^{1}=0.335, d_{002}^{2}=0.337, d_{002}^{3}=0.340$, $d_{002}^{4}=0.3425, \quad d_{002}^{5}=0.3440 \quad$ и $\quad d_{002}^{6}=0.355 / 0.368 \mathrm{~nm}$. Поэтому аналогично [12] провели разделение экспериментально наблюдаемых асимметричных дифракционных максимумов на минимальное количество симметричных компонент, описываемых функцией Гаусса, и сопоставили вычисленные значения $d_{002}$ с данными, приведенными в [14-18]. Рассмотрим первоначально результаты анализа профилей асимметричных дифракционных максимумов ОКР, ориентированных параллельно оси нити $\left(\varphi=0^{\circ}\right.$, табл. 2,3$)$.

Асимметричные максимумы 002 и 004 ОКР УВ, полученных при наиболее высокой в условиях эксперимента температуре (вытяжка жгута составила 7.5\%), хорошо разлагается на три компоненты, отличающиеся положением центра тяжести, значением интегральной ширины и площади. Суммарный максимум компонент отчетливо совпадает с экспериментально наблюдаемым, в том числе и при асимптотическом приближении к линии фона (коэффициент детерминации $R^{2} \sim 0.998$ ) (рис. $3, a$ ). Результаты вычисления $L_{002}$ и $d_{002}$ по интегральной ширине и центру тяжести трех компонент приведены в табл. 2. Обозначим эти компоненты $K_{2}, K_{3}$ и $K_{5}$, поскольку вычисленные значения межслоевых расстояний наиболее близки к приведенным в $[14-18] d_{002}^{2}=0.337$, $d_{002}^{3}=0.340, d_{002}^{5}=0.3440 \mathrm{~nm}$. Компонентный состав и размеры ОКР материала УВ существенно зависят от температуры обработки, определяющей вытяжку жгута. При вытяжке 7.0\% сформировались компоненты $K_{2}$, $K_{4}$ и $K_{5}$, при 6.5 и $6.0 \%$ - компоненты $K_{3}, K_{4}$ и $K_{5}$, при $5.5 \%-K_{3}, K_{5}$ и $K_{6}$. Средние размеры ОКР наибольшие для компоненты $K_{2}$ и наименьшие для $K_{6}$.

На рис. 3, $b$ и в табл. 3 приведены результаты разделения экспериментально наблюдаемых асимметричных дифракционных максимумов 004 на минимальное количество симметричных компонент, описываемых функцией Гаусса. Средние размеры ОКР и межплоскостное расстояние компонент УВ, вычисленные по результатам разложения профиля максимума 004, достаточно хорошо соответствуют таковым, приведенным выше.

Рассмотрим зависимость компонентного состава и размеров $L_{002}$ от угла $\varphi$ ориентировки ОКР относительно оси нити. На рис. 3, $c$ приведены для примера 
Таблица 4. Параметры структуры, вычисленные по центру тяжести и интегральной ширине компонент разложения асимметричных дифракционных максимумов 100 и 110

\begin{tabular}{|c|c|c|c|c|c|c|}
\hline Вытяжка УВ, \% & $d_{100}, \mathrm{~nm}$ & $L_{100}, \mathrm{~nm}$ & $\begin{array}{c}\text { Содержание } \\
\text { компонент, \% }\end{array}$ & $d_{100}, \mathrm{~nm}$ & $L_{100}, \mathrm{~nm}$ & $\begin{array}{c}\text { Содержание } \\
\text { компонент, \% }\end{array}$ \\
\hline \multirow[t]{2}{*}{7.5} & 0.2134 & 15.1 & 56 & 0.1233 & 16.9 & 83 \\
\hline & 0.2121 & 5.1 & 44 & 0.1229 & 5.8 & 17 \\
\hline \multirow[t]{2}{*}{7.0} & 0.2135 & 13.3 & 57 & 0.1231 & 16 & 57 \\
\hline & 0.2111 & 4.5 & 43 & 0.1222 & 5.5 & 43 \\
\hline \multirow{2}{*}{6.5} & 0.2133 & 13.0 & 58 & 0.1231 & 16.7 & 59 \\
\hline & 0.2110 & 4.9 & 42 & 0.1223 & 5.4 & 41 \\
\hline \multirow[t]{2}{*}{6.0} & 0.2133 & 13.6 & 55 & 0.1231 & 16.6 & 48 \\
\hline & 0.2116 & 4.8 & 45 & 0.1224 & 6.1 & 52 \\
\hline \multirow[t]{2}{*}{5.5} & 0.2133 & 11.0 & 53 & 0.1229 & 11.9 & 45 \\
\hline & 0.2102 & 4.9 & 47 & 0.1213 & 3.8 & 55 \\
\hline \multirow[t]{2}{*}{ Исходное УВ } & 0.2126 & 8.6 & 51 & 0.1227 & 7.9 & 45 \\
\hline & 0.2093 & 3.7 & 49 & 0.1209 & 3.2 & 55 \\
\hline
\end{tabular}

дифракционные максимумы 002 ОКР, ориентированных в угловом интервале $\varphi$ от 0 до $8^{\circ}$. Интенсивность максимумов по мере увеличения угла $\varphi$ быстро уменьшается (так, например, отношение интенсивности при $\varphi=7^{\circ}$ к таковому при $\varphi=0^{\circ}$ составляет 0.1$)$. Поэтому ограничились анализом профилей наиболее интенсивных дифракционных максимумов 002 при $\varphi=0,1,2, \ldots 6^{\circ}$. Наиболее существенные изменения компонентного состава и размеров ОКР при увеличении угла $\varphi$ наблюдаются в УВ, относительное удлинение которого составило 7.5\% (табл. 2). В интервале углов $\varphi$ от 0 до $2^{\circ}$ регистрируются ОКР, которые по значениям межплоскостных расстояний можно отнести к компонентам $K_{2}, K_{3}$ и $K_{5}$, в интервале $\varphi$ от 3 до $6^{\circ}-K_{3}, K_{4}$ и $K_{5}$.

В результате термомеханической обработки при более низкой температуре, соответствующей вытяжке жгута на 7.0\%, в УВ формируются ОКР, значения межслоевых расстояний которых в угловых интервалах $\varphi$ от 0 до $2^{\circ}$ и от 3 до $6^{\circ}$ наиболее близки к компонентам $K_{2}, K_{4}, K_{5}$ и $K_{3}, K_{4}, K_{5}$ соответственно. В процессе термообработки УВ при относительном удлинении жгута на $6.5 \%$ в исследованном угловом интервале $\varphi$ от 0 до $6^{\circ}$ формируются компоненты, две из которых по значениям $d_{002}$ и, учитывая достаточно большие размеры ОКР при $\varphi$, равном 4 и $5^{\circ}$, можно отнести к $K_{3}$ и $K_{4}$. Третьей компонентой являются $K_{5}$ или $K_{6}$ в угловом интервале $\varphi$ от 0 до $3^{\circ}$ и от 4 до $6^{\circ}$ соответственно. Компонентный состав УВ, полученного при относительном удлинении жгута $6.0 \%$, близок к таковому выше описанного волокна.

При самой низкой температуре дополнительной обработки $\left(\ell / \ell_{0}=5.5 \%\right)$ компонента $K_{3}$ сформировалась только при ориентировке ОКР параллельно оси нити. Углеродный материал волокна в угловом интервале ориентировок $\varphi$ от 1 до $6^{\circ}$ состоит из ОКР, которые по значениям $d_{002}$ можно отнести к компонентам $K_{4}, K_{5}$ и $K_{6}$. Следует отметить, что во всех исследованных образцах УВ наблюдается тенденция уменьшения размеров ОКР одной и той же компоненты в направлении 002 по мере увеличения угла $\varphi$.
Асимметричные дифракционные максимумы 100 и 110 УВ достаточно уверенно разлагаются на две компоненты, описываемые функцией Гаусса (коэффициент детерминации $\left.R^{2} \sim 0.98\right)$. Положение наиболее интенсивных выделенных максимумов соответствует рассеянию рентгеновского пучка ОКР, межплоскостные расстояния которых $d_{100}$ и $d_{110}$ близки к табличным значениям (0.21319 и $0.12308 \mathrm{~nm}$, № 00-056-0159, PDF-2) (табл. 4.) Средние размеры таких ОКР $L_{100} \sim 11-15 \mathrm{~nm}$, $L_{110} \sim 12-17 \mathrm{~nm}$. Размеры ОКР второй компоненты в 2.5-3 раза меньше. Значения соответствующих межплоскостных расстояний на $0.5-1.5 \%$ меньше табличных. По мере повышения температуры обработки количество наиболее дисперсной компоненты уменьшается. Результаты анализа асимметричных профилей максимумов 100 и 110 позволяют предположить, что в углеродном материале формируются структуры, параметры которых в направлениях 100 и 110 отличаются от таковых графита.

Таким образом, полученные данные по анализу профиля максимумов 002 и 004 исследованных волокон и опубликованные ранее результаты [12] указывают на то, что в углеродном материале формируется ряд метастабильных состояний, отличающихся значением межслоевого расстояния и размерами $L_{002}$. Повышение температуры обработки в условиях действия вытягивающей нагрузки стимулирует рекристаллизацию и более активный рост размеров ОКР, ориентированных параллельно оси нити (направлению действия нагрузки). При увеличении угла $\varphi$ наблюдается уменьшение размеров ОКР компонент, а также изменение компонентного состава в сторону образования метастабильных состояний, соответствующих большим значениям $d_{002}$.

На рис. 4 приведены схемы, иллюстрирующие изменения компонентного состава (тонкой структуры) углеродного материала при ориентировке ОКР относительно оси нити под углом $\varphi=0,1,2$ и $3^{\circ}$ в зависимости от температуры получения. Компонента $K_{6}$ присутствует 

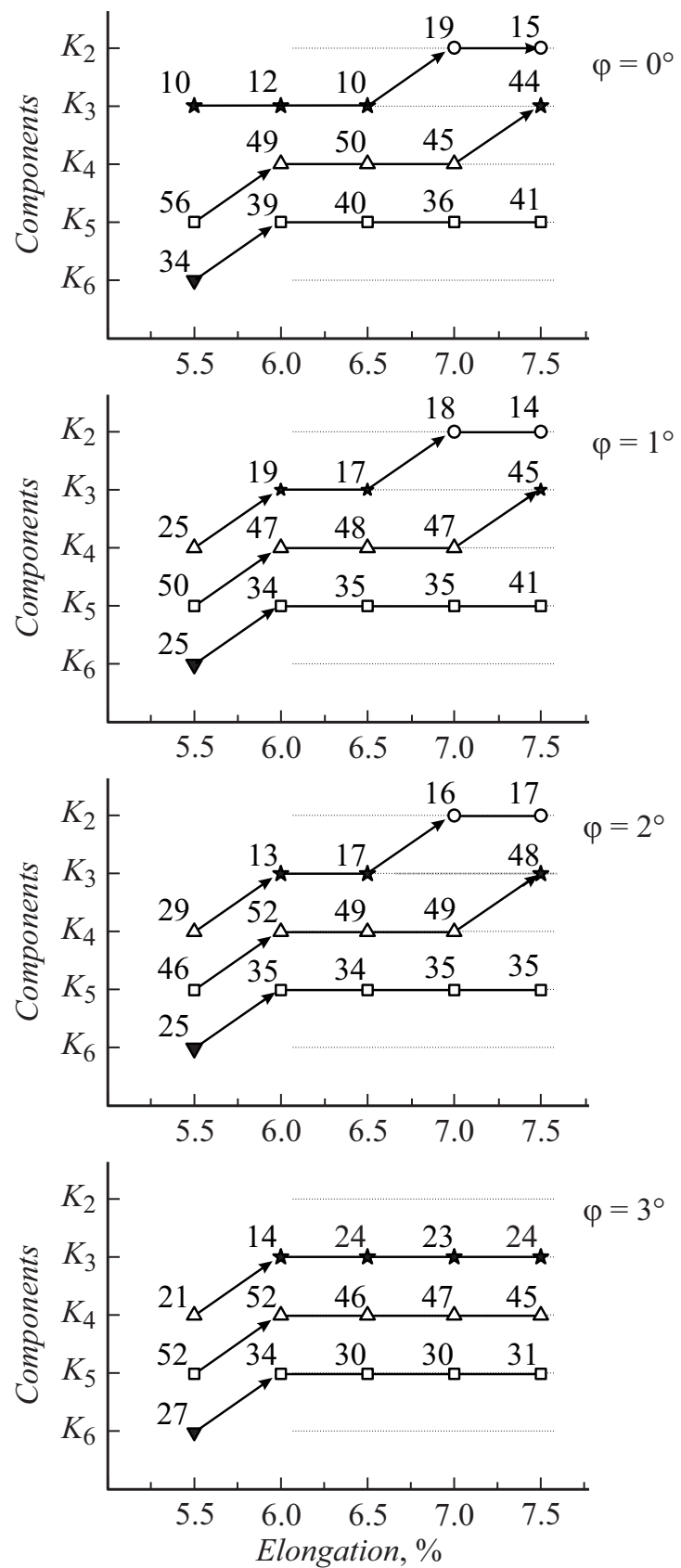

Рис. 4. Изменение компонентного состава материала углеродных волокон по мере повышения температуры получения (относительного удлинения $\left.\ell / \ell_{0}\right)$. Цифрами указано процентное содержание компонент (точность оценки $\sim 10 \%$ ).

только в УВ, полученном при самой низкой (из исследованных) температуре, ее количество для ориентировок $\varphi=0,1,2$ и $3^{\circ}$ составляет $\sim 25-30 \%$. В УВ, полученных при более высоких температурах $\left(\ell / \ell_{0}=6.0\right.$ и $6.5 \%)$, регистрируются компоненты $K_{3}, K_{4}, K_{5}$, затем $\left(\right.$ при $\ell / \ell_{0}=7.0$ и $7.5 \%$ только для $\varphi=0,1$ и $\left.2^{\circ}\right)-K_{2}$, $K_{4}, K_{5}$ и $K_{2}, K_{3}, K_{5}$ соответственно (цифрами на рисунке указано процентное содержание компонент, точность оценки составляет $\sim 10 \%$ ). По-видимому, формирование компонент $K_{2}$ и $K_{3}$ в УВ при $\ell / \ell_{0}=7.5 \%$ обусловило наиболее существенное уменьшение параметра текстуры $Z$ материала (табл. 1).

Материал УВ по таким параметрам, как размеры ОКР $L_{002}$ и межслоевое расстояние $d_{002}$, становится наиболее гетерогенным. Можно предположить, что при этом режиме получения начинает формироваться радиальная неоднородность филамента — наибольшие изменения структуры происходят в приповерхностном слое нити. Такая неоднородность УВ, полученного при высокой $\left(\sim 3000^{\circ} \mathrm{C}\right)$ температуре, отчетливо наблюдалась авторами [19] по сечению филамента методом микрокартографирования комбинационного рассеяния.

\section{Выводы}

Анализ профилей дифракционных максимумов углеродного волокна позволяет получить данные о его тонкой структуре.

В процессе высокотемпературной термомеханической обработки развивается рекристаллизация углеродного материала, сопровождающаяся формированием метастабильных состояний, структурные параметры которых зависят от температуры обработки.

Повышение температуры обработки в условиях действия вытягивающей нагрузки стимулирует более активный рост размеров областей когерентного рассеяния, ориентированных параллельно оси нити, углеродный материал волокон становится более гетерогенным. При увеличении угла $\varphi$ наблюдается уменышение размеров областей когерентного рассеяния компонент, а также изменение компонентного состава в сторону образования метастабильных состояний, соответствующих большим значениям $d_{002}$.

\section{Финансирование работы}

Работа выполнена при финансовой поддержке Федерального государственного бюджетного образовательного учреждения высшего образования „Челябинский государственный университет".

\section{Конфликт интересов}

Авторы заявляют, что у них нет конфликта интересов

\section{Список литературы}

[1] Zhua C.Zh., Yua X.L., Liua X.F., Maoc Y.Z., Liua R.G., Zhaoa N., Zhanga X.L., Xua J. // Chinese J. Polymer Sci. 2013. Vol. 31. N 5. P. 823-832.

[2] He D.X., Wang C.G., Bai Y.J., Lun N., Zhu B., Wang Y.X. // J. Mater. Sci. 2007. Vol. 42. N 17. P. 7402-7407.

[3] Wen Y., Li H., Peng G., Yang Y., Liu L. // Mater. Sci. Poland. 2010. Vol. 28. N 2. P. 479-490.

[4] Wang B., Xiao Sh., Cao W., Shi X., Xu L. // J. Appl. Polymer Sci. 2012. Vol. 124. P. 3413-3418.

[5] Fazlitdinova A.G., Tuymentsev V.A., Podkopaev S.A., Shveikin G.P. // J. Mater. Sci. 2010. Vol. 45. P. 3998-4005. 
[6] Rahaman M.S.A., Ismail A.F., Mustafa A. // Polymer Degradation and Stability. 2007. Vol. 92. P. 1421-1432.

[7] Sauder C., Lamon J., Pailler R. // Composit. Sci. Technol. 2002. Vol. 62. P. 499-504.

[8] Oya N., Johnson D.J. // Carbon. 2001. Vol. 39. P. 635-645.

[9] Ozbek S., Isaac D.H. // Carbon. 2000. Vol. 38. P. 2007-2016.

[10] Liu F., Wang H., Xue L., Fan L., Zhu Zh. // J. Mater. Sci. 2008. Vol. 43. N 12. P. 4316-4322.

[11] Li D., Wang H., Wang X. // J. Mater. Sci. 2007. Vol. 42. P. 4642-4649.

[12] Тюменцев В.А., Фазлитдинова А.Г. // ЖТФ. 2016. Т. 86. Вып. 3. С. 62-69.

[13] Zhang Y., Tajaddod N., Song K., Minus M.L. // Carbon. 2015. Vol. 91. P. 470- 493.

[14] Lachter J., Bragg R.M. // Phys. Rev. B. 1986. Vol. 33. N 12. P. 8903-8905.

[15] Tadjani M., Lechter Jacil, Kabret T.S., Bragg R.H. // Carbon. 1986. Vol. 24. N 4. P. 447-449.

[16] Kawamura K., Bragg R.H. // Carbon. 1986. Vol. 24. N 3. P. 301-309.

[17] Aladekomo J.B., Bragg R.H. // Carbon. 1990. Vol. 28. N 6. P. 897-906.

[18] Wang C.S., Wu G.T., Li W.Z. // J. Power Sources. 1998. Vol. 76. P. 1-10.

[19] Букалов С.С., Лейтес Л.А., Головешкин А.С., Тюменцев В.А., Фазлитдинова А.Г. Исследование строения углеродного волокна, полученного путем высокотемпературной термомеханической обработки полиакрилнитрильной нити, методами спектроскопии комбинационного рассеяния и рентгеновской дифрактометрии. // Изв. РАН. Серия химическая. 2018. № 6. С. 1002-1009. 